\title{
Caracterização da crosta do Brasil central: uma análise por função do receptor (FR)
}

Cíntia Rocha da Trindade ${ }^{1}$, José Eduardo P. Soares ${ }^{1}$, Reinhart A. Fuck' ${ }^{1}$ Adriana Chatack Carmelo ${ }^{1}$

${ }^{1}$ Laboratório de Estudos da Litosfera (LabLitos), Instituto de Geociências, Universidade de Brasília- UnB

Copyright 2014, SBGf - Sociedade Brasileira de Geofísica

Este texto foi preparado para a apresentação no VI Simpósio Brasileiro de Geofísica, Porto Alegre, 14 a 16 de outubro de 2014. Seu conteúdo foi revisado pelo Comitê Técnico do VI SimBGf, mas não necessariamente representa a opinião da SBGf ou de seus associados. É proibida a reprodução total ou parcial deste material para propósitos comerciais sem prévia autorização da SBGf.

\section{Resumo}

A crosta do Brasil central foi estruturada no Neoproterozóico como consequência da colisão dos paleocontinentes São Francisco, Amazônico, Paranapanema e Parnaíba. Novas determinações de espessura crustal obtidas por função do receptor, somadas aos dados da literatura, foram utilizadas para gerar mapa de profundidade da Moho trazendo novos vínculos para 0 entendimento da evolução tectônica do Brasil central. A Moho apresenta geometria irregular, com profundidades entre 33 e $53 \mathrm{~km}$, e valores característicos para os diferentes domínios tectônicos. Esses resultados em conjunto com dados de gravimetria e topografia permitem concluir que o equilíbrio isostático regional é alcançado, principalmente, por variações nas propriedades físicas do manto litosférico com menor contribuição crustal e que a estruturação final do Brasil central se deu com a subducção para oeste do Paleocontinente Amazônico.

\section{Introdução}

O Brasil central representa sistema orogênico Neoproterozoico de dimensões continentais cuja evolução recente é marcada principalmente por ajustes verticais, fruto de processos distensivos regionais/globais, que na Placa Sul-Americana, culminaram com a implantação das bacias do Solimões, Amazonas, Parnaíba e Paraná no Paleozoico e a abertura do Atlântico Sul no Mesozoico. Apesar de submetida a processos distensivos de grande monta, a litosfera do Brasil central foi pouco afetada e, consequentemente, sua estrutura crustal está preservada.

Com esse entendimento, há aproximadamente quinze anos, o Laboratório de Estudos da Litosfera (LabLitos), do IG/UnB/Brasil, vem realizando estudos sísmicos e sismológicos no Brasil central, visando caracterizar a estrutura da crosta na região (Fig. 1).

Este trabalho apresenta mapa de profundidade da Moho para o Brasil central $\left(08^{\circ}-14^{\circ} \mathrm{S} / 46^{\circ}-51^{\circ} \mathrm{W}\right)$ obtido a partir de dezessete novas determinações de espessura crustal e razão de Poisson média da crosta a partir do método função do receptor, somadas às determinações da literatura, oriundas de resultados de função do receptor (Assumpção et al., 2004 e 2013; Rosa et al., 2012) e refração sísmica profunda (Berrocal et al., 2004; Soares et al., 2006; Ventura et al., 2011). Os resultados de profundidade da Moho são interpretados em conjunto com resultados de gravimetria e topografia para analisar o equilíbrio isostático regional, a compartimentação tectônica, e consequentemente, a evolução tectônica do Brasil central.

\section{Contexto Geológico}

O Brasil central foi estruturado no Neoproterozoico fruto da aproximação e consequente colisão dos paleocontinentes São Francisco, Paranapanema, Parnaíba e Amazônico, processo que amalgamou também terrenos de dimensões menores como o Arco Magmático de Goiás e o Maciço de Goiás (Pimentel et al., 2000; Fuck et al., 2005; Fuck et al., 2008; BB Neves \& Fuck, 2013).

$\mathrm{Na}$ região de estudo, o Brasil central é formado pelos terrenos da parte norte da Província Tocantins na sua porção central, limitados pelo Cráton São Francisco a leste, Cráton Amazônico a oeste e Bacia do Parnaíba a norte (Fig. 1).

A parte norte da Província Tocantins é constituída pela Faixa Araguaia, bordejando o limite leste do Cráton Amazônico, e a Faixa Brasília, perfazendo o limite oeste do Cratón São Francisco. Por sua vez a Faixa Brasília é dividida, de oeste para leste, nos terrenos do Arco Magmático de Goiás, Maciço de Goiás com porções arqueana e paleoproterozoica, e zona externa da Faixa Brasília. Os terrenos granulíticos da região de Porto Nacional representam porção de crosta continental paleoproterozoica considerada embasamento da Faixa Araguaia.

A Bacia do Parnaíba a norte, com área de aproximadamente $660.000 \mathrm{~km}^{2}$, representa extensa sinéclise paleozoica (Castro et al., 2014).

Como resultado final, o Brasil central apresenta trend geológico N-S na Faixa Araguaia e NE-SW na Faixa Brasília, onde a trama do embasamento encontra-se fortemente influenciada pelo Lineamento Transbrasiliano. Relacionado com os terrenos do Arco Magmático de Goiás a sul e aos granulitos da região de Porto Nacional a norte, ocorre expressivo alto gravimétrico regional (Soares et al., 2006). Os terrenos do Arco Magmático de Goiás sugerem continuidade por sob a Bacia do Parnaíba, seguindo tendência do Lineamento Transbrasiliano. No entanto, 0 alto gravimétrico é interrompido e deslocado para oeste, acompanhando o limite da Faixa Araguaia.

\section{Metodologia}

Função do receptor é um método sismológico que permite isolar a estrutura da Terra sob a estação sismográfica dos efeitos da fonte e de estruturas distantes. A técnica desenvolvida por Langston (1979) utiliza registros telessísmicos com distância epicentral 
entre $30^{\circ}$ e $90^{\circ}$ para determinar as descontinuidades mais marcantes sob a estação sismográfica. É comumente utilizado na determinação da espessura crustal e razão de Poisson (Vp/Vs) médias da crosta.

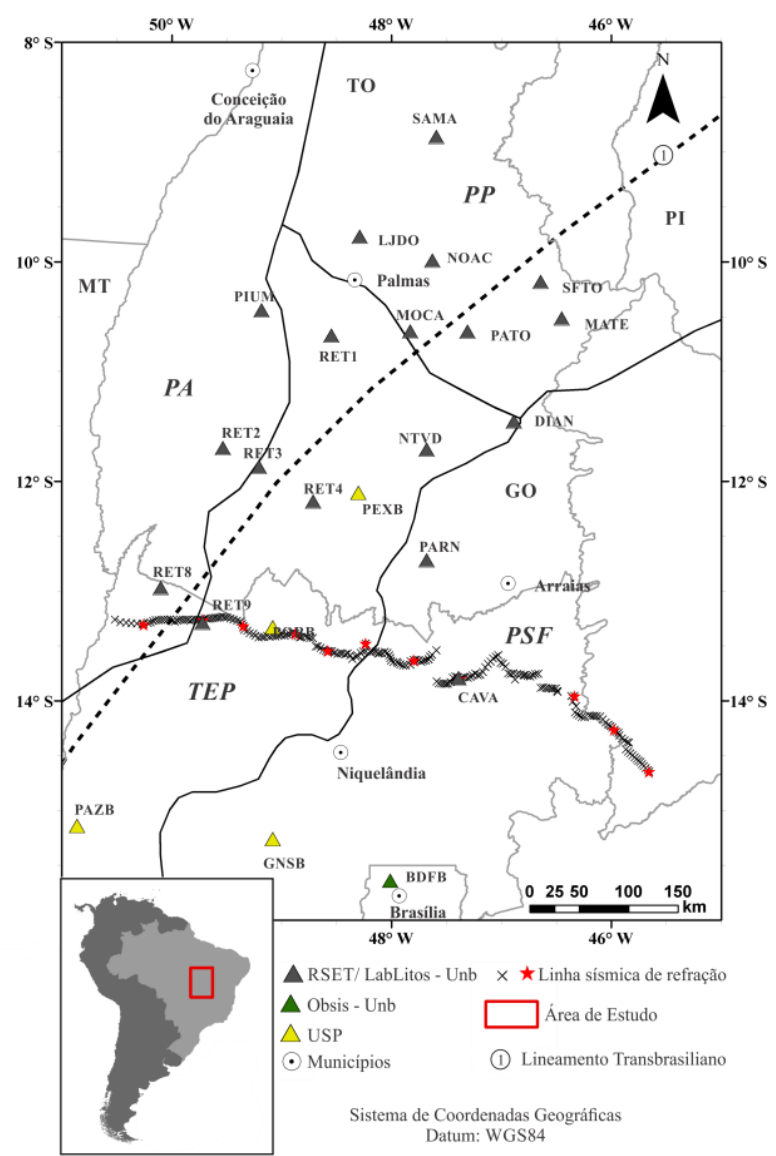

Figura 1- Mapa de localização da área de estudo com limites estaduais $e$ tectônicos. PAPaleocontinente Amazônico (Cratón Amazônico+Faixa Araguaia), PPPaleocontinente Parnaíba (Bacia do Parnaíba), TEP - Terrenos entre Paleocontinentes (terrenos do Arco Magmático de Goiás e Maciço de Goiás) e PSF - Paleocontinente do São Francisco (zona extena da Faixa Brasília+ Cratón do São Francisco).

Quando uma frente de onda $\mathrm{P}$ de um telessismo incide sobre uma descontinuidade abaixo de uma estação sismográfica, com ângulo próximo a vertical, parte da sua energia é convertida em onda $S$ vertical e parte em ondas $S$ múltiplas. $O$ registro da onda $P$ será predominante na componente vertical e da onda $S$ (produzida na conversão), principalmente na radial. A deconvolução da componente vertical de registro da componente radial fornece a estrutura da Terra sob a estação sismográfica na forma de uma série temporal com o primeiro pulso representando a onda $\mathrm{P}$ e demais pulsos ondas $S$ direta e múltiplas, representativas das descontinuidades de subsuperfície.

O banco de dados utilizado compreende telessismos registrados em estações sismográficas de banda-larga da rede sismográfica para estudos tectônicos do
LabLitos, com magnitude a partir de $5,5 \mathrm{mb}$ e distância epicentral entre $30^{\circ}$ e $90^{\circ}$, adquiridos entre julho/2008 e janeiro/2014 (Fig. 2).

O processamento de dados seguiu as etapas abaixo:

i) os parâmetros de fonte (latitude, longitude, profundidade, hora origem) foram obtidos do catálogo do USGS (http://neic.usgs.gov);

ii) os eventos foram convertidos para o formato SAC e cortados em janelas de registro de 150 segundos (60s antes e 90s após a chegada do evento); iii) os traços de função do receptor foram gerados no domínio da frequência, utilizando pacote de Ammon (1991), com valor de nível d'água de 0,001 e parâmetro a do filtro Gaussiano igual a 4;

iv) por inspeção visual, foram selecionados os traços de função do receptor com boa razão sinal-ruído;

v) para as estações sem dependência azimutal, os traços de função do receptor com parâmetro de raio (p) próximos foram empilhados;

vi) a estação RET3, por apresentar dependência azimutal, teve seus traços somados para parâmetros de raio próximos, segundo os azimutes NW e SE;

vii) a espessura da crosta $(H)$ versus a razão de Poisson (Vp/Vs) foi obtida pelo programa HK-Stacking (Zhu \& Kanamori, 2000);

viii) as estações com banco de dados reduzido (DIAN, PARN, NOAC) e aquelas instaladas sobre coberturas cretáceas do Grupo Urucuia (SFTO, MATE, PATO), cujos resultados são fortemente influenciados por camada sedimentar rasa, tiveram espessuras determinadas a partir da leitura direta das fases Ps. Os valores de $\mathrm{Vp} / \mathrm{Vs}$ foram obtidos a partir de resultados de estações sismográficas próximas.

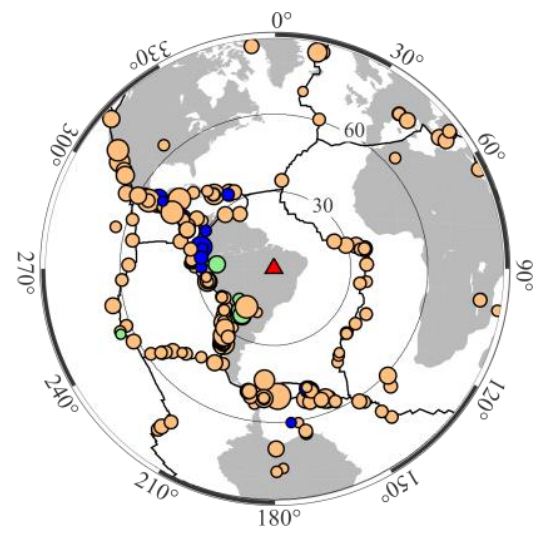

Eventos selecionados durante julho/2008 a janeiro/2014 \begin{tabular}{|c|c|c|c|}
\hline Profundidade $(0-100 \mathrm{~km})$ & $\bullet$ Profundidade $(100-300 \mathrm{~km})$ & $\diamond$ Profundidade $(300 \mathrm{~km})$ \\
\hline $\mathrm{M} 5$ & $\mathrm{M}$ & $\mathrm{MB}$
\end{tabular}

Figura 2- Localização epicentral dos eventos utilizados para gerar função do receptor.

\section{Resultados}

Os resultados de função do receptor obtidos, associados aos resultados de espessuras crustais da literatura (Soares et al., 2006 e Assumpção et al., 2004 e 2013), permitiram gerar mapa de profundidade da Moho para o Brasil central. Esse mapa mostra Moho 
irregular com profundidades entre $33-53 \mathrm{~km}$, com valores de espessura crustal variando de acordo com os domínios tectônicos (Fig. 4).

A Bacia do Parnaíba é caracterizada por crosta de espessura de 44-45 km e razão $\mathrm{Vp} / \mathrm{Vs}$ média de 1,71.

A zona externa da Faixa Brasília norte apresenta crosta de $40 \mathrm{~km}$ e $\mathrm{Vp} / \mathrm{Vs}=1,70$, contrastando em espessura com a crosta da bacia e sugerindo contato abrupto entre esses dois domínios. A sul, a zona externa da Faixa Brasília, dominada por coberturas metassedimentares, apresenta espessura de $42-44 \mathrm{~km}$ e $V p / V s=1,70$.

O Arco Magmático de Goiás apresenta crosta com espessura variando de $35 \mathrm{~km}$ na porção sul a $42 \mathrm{~km}$ em regiões mais norte, com $\mathrm{Vp} / \mathrm{Vs}$ de 1,70-1,71. A norte-noroeste do arco os terrenos granulíticos da região de Porto Nacional possuem crosta de $41,5 \mathrm{~km}$ e $\mathrm{Vp} / \mathrm{Vs}$ de 1,78. Ambos os terrenos ocupam porção dominada pelo alto gravimétrico do Brasil central.

No oeste da área, domínio da Faixa Araguaia a crosta apresenta espessura de $49 \mathrm{~km}$ e $\mathrm{Vp} / \mathrm{Vs}$ de 1,79 na parte norte e $40 \mathrm{~km}$ e $\mathrm{Vp} / \mathrm{Vs}$ de 1,78 a sul, acusando possível descontinuidade.

Ao longo do limite oeste do alto gravimétrico do Brasil central, os resultados das estações RET9 (Fig. 3), RET3 e PIUM mostram crosta anormalmente espessa com profundidades da Moho em torno de $53 \mathrm{~km}$ (Vp/Vs $<1,70$ ), sugerindo possível duplicação crustal.

Nas latitudes $13^{\circ}-14^{\circ} \mathrm{S}$, a interpretação conjunta de dados de refração sísmica profunda e função do receptor permitiu imagear a estrutura da crosta e identificar a frente de colisão da Paleoplaca Amazônica com o Arco Magmático de Goiás, caracterizada (dentre outras evidências) por degrau abrupto de mais de 15 $\mathrm{km}$ na descontinidade de Moho e, em superfície, por obducção de lasca de crosta arquena (2,9 Ga) encravada em terrenos juvenis (630-540 Ma) do Arco Magmático de Goiás (Soares et al., 2006; Ventura et al., 2011). A norte, a estação RET3 apresenta resultados de função do receptor com forte dependência azimutal, com valores de espessura crustal de $53 \mathrm{~km}$ para eventos com epicentro a NW da estação e de $41 \mathrm{~km}$ para eventos com epicentro a SE, marcando a continuidade do degrau imageado a sul. A estação PIUM confirma a continuidade do degrau para norte apresentando profundidade de $53 \mathrm{~km}$ para a Moho.

\section{Discussão e Conclusões}

Os resultados de espessura crustal em conjunto com a anomalia gravimétrica Bouguer e topografia (Fig. 4; Fig.5) mostram que a variação de espessura crustal não reflete a variação da resposta gravimétrica observada, sugerindo que o equilíbrio isostático regional seja alcançado principalmente por variações nas propriedades físicas das rochas do manto litosférico, com menor contribuição crustal.

O alto gravimétrico Bouguer do Brasil central não é compensado na crosta, marca corredor de manto Neoproterozoico (quente e primitivo), em contraste com manto Arqueano-Paleoproterozoico, depletados e frios, dos domínios adjacentes (Soares et al., 2006). Dessa forma a resposta gravimétrica permite delimitar 0 Paleocontinente São Francisco, formado pelos domínios do Cráton São Francisco mais zona externa da Faixa Brasília, o Paleocontinente Amazônico, formado pelo Cráton Amazônico mais Faixa Araguaia, - Paleocontinente Parnaíba, encoberto pelos sedimentos da Bacia do Parnaíba, e os terrenos relacionados ao alto gravimétrico, representados pelo Arco Magmático de Goiás, Maciço de Goiás e granulitos de Porto Nacional, amalgamados entre os blocos maiores (Fig.1; Fig.5).
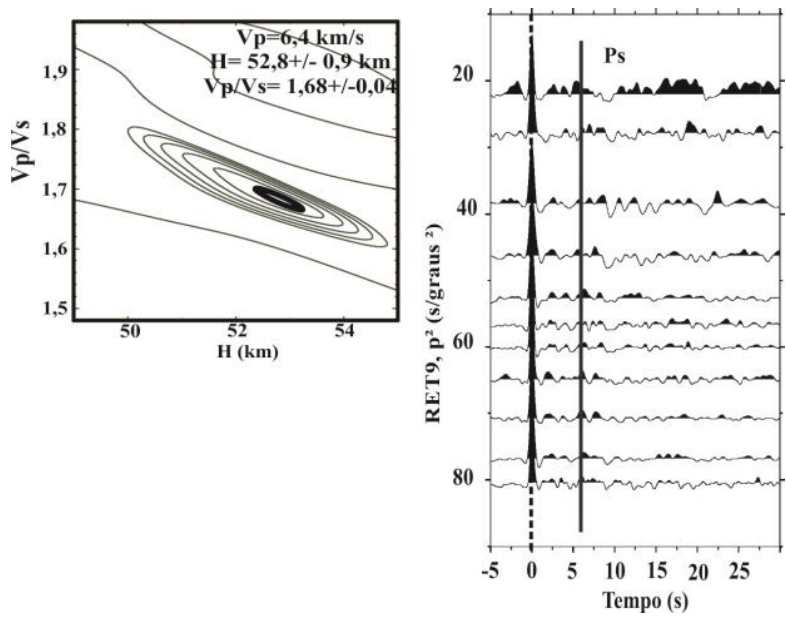

Figura 3- Estimativa da espessura e razão $\mathrm{Vp} / \mathrm{Vs}$ da crosta sob a estação RET9, obtidos pelo programa HK-stacking, e traços empilhados de função do receptor radial.

A região de sutura da Paleoplaca Amazônica no Brasil central passa a leste da Faixa Araguaia, perfazendo o limite com o Arco Magmático de Goiás a sul (13요), com os terrenos granulíticos de Porto Nacional na porção central $\left(10^{\circ} \mathrm{S}-12^{\circ} \mathrm{S}\right)$ e com a Bacia do Parnaíba mais a norte.

O conjunto de dados disponíveis permite traçar cenário de evolução para o Brasil central, que de forma geral se resume às etapas: i) subdução para oeste da porção oceânica da Paleoplaca São Francisco; (ii) colisão do Paleocontinente São Francisco com os terrenos de arco de ilha e com o Paleocontinente Parnaíba a nortenoroeste. Possivelmente os terrenos de arco de ilha continuam sob os sedimentos da Bacia do Parnaíba, perfazendo o limite entre os paleocontinentes São Francisco e Parnaíba; (iii) com a continuação dos esforços, a subducção foi invertida com consumo para leste da porção oceânica da Paleoplaca Amazônica. A região de sutura está bem caracterizada por duplicação crustal; (iv) eventos distensivos posteriores (Paleozoico e Mesozoico) provocaram ajustes isostáticos regionais que culminaram com implantação da Bacia do Parnaíba na porção norte da área.

\section{Agradecimentos}

A Capes pela bolsa de mestrado a C. Trindade, ao INCT para Estudos Tectônicos e ao Projeto Transbrasiliano pelo suporte aos trabalhos de campo e ao LabLitos pelo fornecimento dos dados para a realização da pesquisa. 


\section{Referências}

Ammon, C.J., 1991. The isolation of receiver effects from teleseismic $\mathrm{P}$ waveforms, Bull. Seismol. Soc. Am., 81 (6), 2504-2510.

Assumpção, M., Bianchi, M.B., M., França, G.S.L., Rocha, M., Barbosa, J.R., Berrocal, J., 2004. Seismic studies of the Brasilia Fold Belt as the western border of the São Francisco Craton, Central Brazil, Tectonophysics, 388, 173-185.

Assumpção, M., Bianchi, M.B., Jordi J., Dias, F.L., França, G.S.L., Nascimento, R., Stéphane, D., Pavão, C.G., Albuquerque., D.F., 2013. Crustal thickness map of Brazil: Data compilation and main features, J. South Am. Earth Sci., 43, 74-85.

B.B. Neves, B., Fuck, R.A., 2013. Neoproterozoic evolution of the basement of the South-American platform, J. S. Am. Earth Science, 47,72-89.

Berrocal, J., Marangoni, Y., Côgo, S. N., Fuck R.A., Soares, J.E.P., Dantas, E., Perosi, F., Fernandes C., 2004. Deep seismic refraction and gravity crustal model and tectonic deformation in Tocantins Province, Central Brazil, Tectonophysics, 388, 187-199.

Castro, D.L., Fuck, R.A., Phillips, J.D., Vidotti, R.M., Bezerra, F.H.R., Dantas, E.L., 2014. Crustal structure beneath the Paleozoic Parnaíba Basin revealed by airborne Crustal structure beneath the Paleozoic Parnaíba Basin revealed by airborne gravity and magnetic data, Brazil, Tectonophysics, 614, 128-145.

Fuck, R.A., Pimentel, M.M., Soares, J.E.P., Dantas, E.L., 2005. Compartimentação da Faixa Brasília. In: SBG, Simpósio de Geologia do Centro-oeste, Atas, 9, .26-27.

Fuck, R.A., BB Neves, B., Schobbenhaus, C., 2008. Rodinia descendants in South America, Precambrian Research, 160, 108-126

Langston, C. A., 1979. Structure under Mount Rainier, Washington, inferred from teleseismic body waves, J. Geophys. Res., 85, 4749-4762.

Pimentel, M.M., Fuck, R.A., Jost, H., Ferreira, C.F.F., Araújo, S.M., 2000. The basement of the Brasília fold belt and the Goiás Magmatic Arc. Tectonic Evolution of South America, 31, 195-230.

Rosa, J. W. C., Rosa, J. W. C. \& Fuck, R. A., 2012. Crust and upper mantle structure in central Brazil derived by receiver functions and SKS splitting analysis. J. South Am. Earth Sci., 34, 33-46.

Soares, J.P., Berrocal, J., Fuck, R.A., Mooney ,W., Ventura, D.B.R., 2006. Seismic characteristics of central Brazil crust and upper mantle: a deep seismic refraction study, J. Geophys. Res., 111, B12302.

Ventura, D. B. R., Soares, J.E.P., Fuck, R. A., Caridade, L.C.C., 2011. Caracterização sísmica e gravimétrica da litosfera sob a linha de refração sísmica profunda de Porangatu, Província Tocantins, Brasil Central, Rev. Bras. Geociênc, 41, 130-140.

Zhu, L. \& Kanamori, H., 2000. Moho depth variation in southern Califórnia from teleseismic receiver functions, J. Geophys. Res.,105, 2696-2980. 


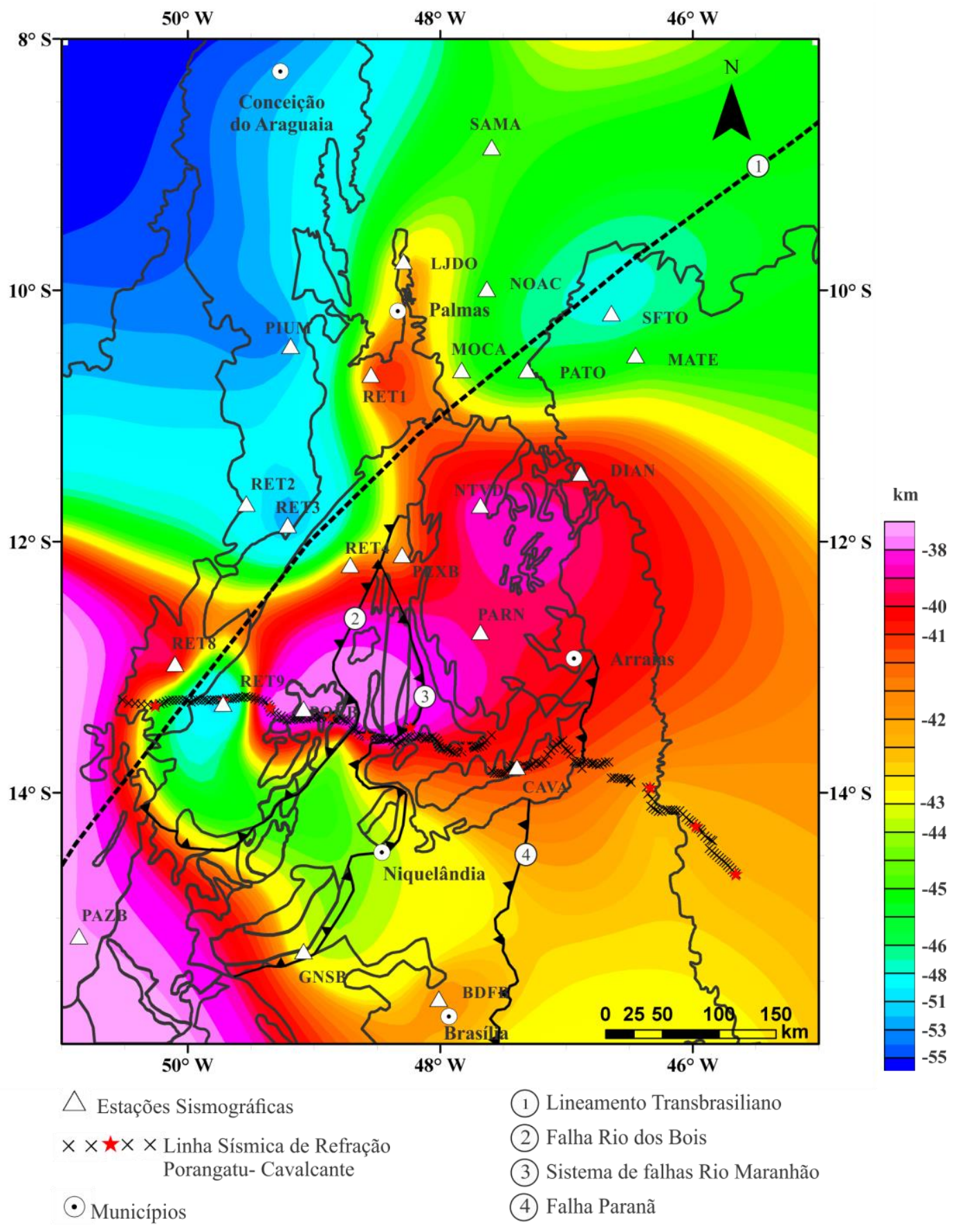

Sistema de Coordenadas Geográficas Datum: WGS84

Figura 4- Mapa de profundidade da Moho, com os limites geológicos do Cráton Amazônico a oeste, Província Tocantins na porção central, Bacia do Parnaíba a norte e Cráton do São Francisco a leste. 


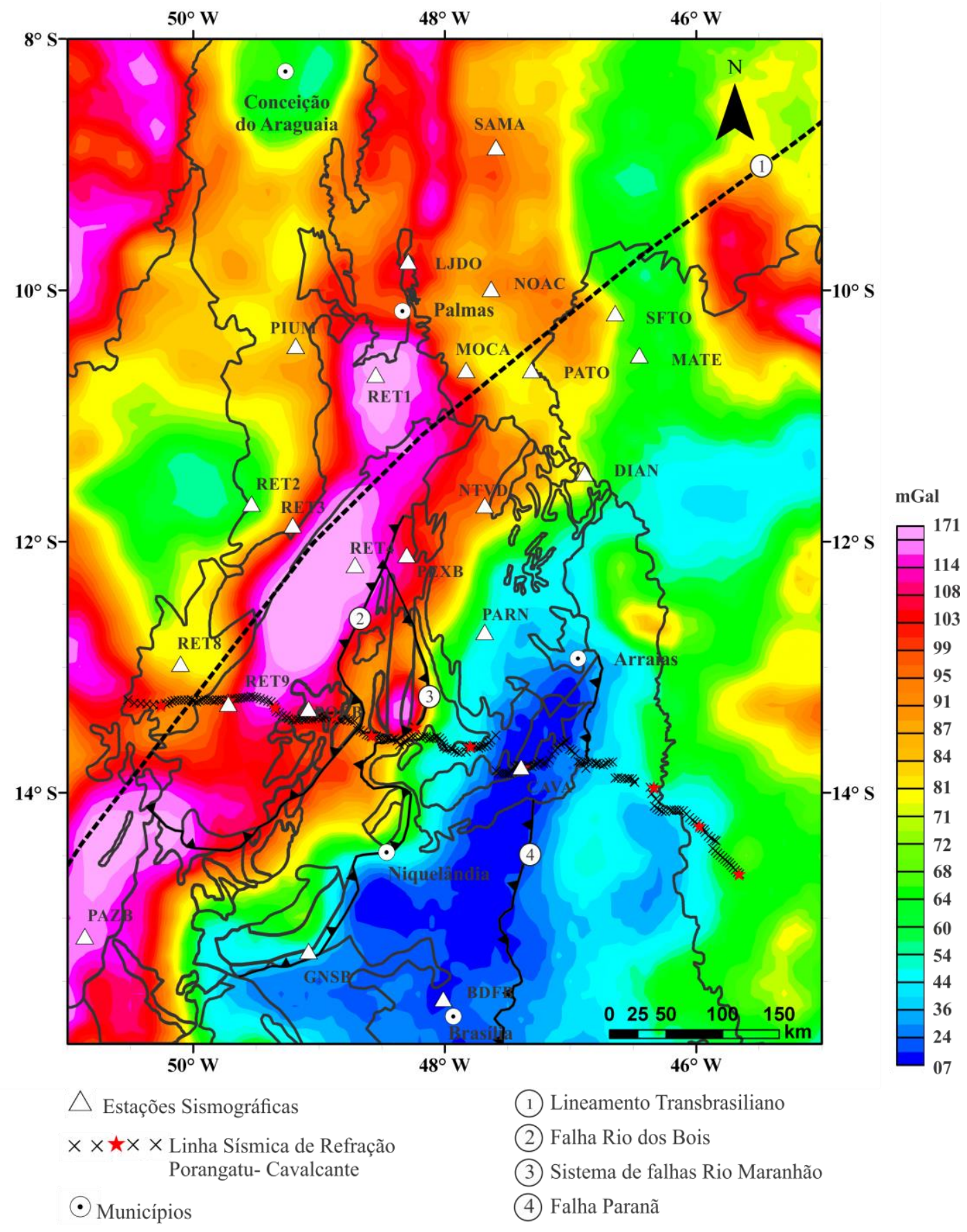

Sistema de Coordenadas Geográficas Datum: WGS84

Figura 5- Mapa de Anomalia Bouguer com os limites geológicos do Brasil central, mostrando a localização das estações sismográficas e linha sísmica de refração. 